\title{
A CONSTITUIÇÃO DOS VÍNCULOS E ESTILOS FAMILIARES QUANDO OS FILHOS FAZEM USO DAS DROGAS
}

DOI: $10.22289 / 2446-922 X . V 3 N 1 A 9$

\author{
Bruna dos Santos Rosa ${ }^{1}$ \\ Gilmar Antoniassi Junior
}

\section{RESUMO}

O presente estudo teve como objetivo desenvolver uma melhor compreensão das relações familiares com adolescentes drogados sob perspectivas sistêmicas, enfatizando a família como um fator competente no resgate de toxicodependentes e a interação entre seus membros, com base nos vários fatores relevantes para a vida em família e vida social. Os fatores culturais, políticos, econômicos e sociais da toxicodependência foram analisados para esclarecer as relações complexas que a droga estabelece com a sociedade, abordando questões como: a complexidade das drogas na sociedade, sua subjetividade e suas relações com o ciclo de vida, especialmente a adolescência em suas crises, entre outros. O uso de abordagens sistêmicas e terapia sistêmica familiar como modelo apresentou uma perspectiva enriquecedora nesse contexto, no sentido de orientar a família para a redefinição de papéis e a reelaboração de suas competências, uma vez que este, encontrando seu equilíbrio, baseado em contexto sobre a experiência e os sentimentos de cada um dos seus membros. Para isso, realizou-se uma pesquisa bibliográfica, utilizando para isso leituras bibliográficas em português com base em livros, monografias, biblioteca virtual em psicologia sobre os tipos de substâncias psicoativas utilizadas pelo homem e seus efeitos fisiológicos e comportamentais, os diversos tratamentos existentes para a dependência química, conceito de família e a relação desta com o envolvimento do adolescente ás drogas, assim como uma explanação sobre sua relevância na recuperação segundo o referencial analítico comportamental. Foi possível concluir, assim, que é importante o desenvolvimento de futuras pesquisas que possam verificar a importância da família para dar suporte e auxiliar o adolescente a deixar o uso de drogas, assim como a eficácia da aplicação da análise do comportamento nos aspectos da dependência química.

Palavras-chave: Drogas. Família. Relações.

\section{ABSTRACT}

The present study aimed to develop a better understanding of family relationships with drugged adolescents under systemic perspectives, emphasizing the family as a competent factor in the rescue of drug addicts and the interaction among their members, based on the

\footnotetext{
${ }^{1}$ Endereço eletrônico de contato: brunatuty2009@hotmail.com

Recebido em 28/06/2017. Aprovado pelo Conselho Editorial e aceito para publicação em 29/06/2017.
} 
various factors relevant to family life and social life. The cultural, political, economic and social factors of drug addiction were analyzed to clarify the complex relationships that the drug establishes with society, addressing issues such as: the complexity of drugs in society, its subjectivity and its relations with the life cycle, especially Adolescence in their crises, among others. The use of systemic approaches and family systemic therapy as a model presented an enriching perspective in this context, in the sense of guiding the family to the redefinition of roles and the re-elaboration of their competences, once this, finding its balance, based on context on The experience and the feelings of each one of its members. For this, a bibliographical research was carried out, using for this bibliographical readings in Portuguese based on books, monographs, virtual library in psychology on the types of psychoactive substances used by man and Its physiological and behavioral effects, the various treatments for the chemical dependence, family concept and its relationship with the adolescent's involvement in drugs, as well as an explanation about its relevance in the recovery according to the analytical behavioral framework. It was possible to conclude that it is important to develop future research that can verify the importance of the family to support and help the adolescent leave the drug use, as well as the effectiveness of the application of behavioral analysis in aspects of chemical dependence .

Keywords: Drugs. Family. Relations.

\section{INTRODUÇÃO}

A família é o primeiro grupo social o qual o homem está inserido, considerada o núcleo principal das relações sociais estando sujeita a pressões e demandas internas e externas constantes para cumprir as suas funções da procriação e de cuidados dos membros. É parte de uma rede múltipla e complexa que evoca aspectos históricos, culturais, legais e emocionais que constituem seu caminho de evolução, caracterizada pela passagem através de eventos previsíveis e imprevisíveis que marcam a construção de sua história (1).

É impossível pensar em um ambiente familiar onde o ciclo de vida esteja dissociado do desenvolvimento, movimento, crescimento, planejamento e etapas de cada membro que compõe a família. Ambos possuem sentido próprio de existência, mas estão extremamente interligados, pois ambos necessitam de um do outro para obter o equilíbrio entre estabilidade e flexibilidade de ser ${ }^{(2)}$.

Compreender a história da família atual, a partir do estudo de seu ciclo de vida familiar pressupõe em identificar os diferentes movimentos que se constituem as crises familiares, provocadas por tensões da vida cotidiana a partir de relações mais amplas ${ }^{(3)}$. 
Todavia, as tensões ocasionadas pelo uso das drogas têm gerado preocupações nos núcleos familiares, seja, por não saber qual o momento certo de abordar o assunto, ou seja, pelo terror instaurado pelos que fazem uso e os danos causados. Assim, família se percebe no meio do fogo cruzado e vulnerável aos riscos expostos pela vida cotidiana.

Cabe a família, compreender a responsabilidade acerca da transmissão de valores, apesar dos pais cumprirem seu papel na perpetuação das informações, não se têm a garantia de que seus filhos irão absorver tudo e terem boas atitudes. $O$ diálogo e a experiências vividas no núcleo familiar, tendem ser um preditor do risco e a proteção para a vulnerabilidade das drogas. Pois, mesmo em ambientes com recursos limitados e já permeados pelo uso das drogas por um dos membros, é possível pela disponibilidade de informações obtidas através das conversas, e a observação do uso e suas complicações que a família possua uma interação mediada em valores ${ }^{(4)}$.

Devido as grandes taxas de divórcio ou mesmo de mães que assumem sozinha a maternidade, hoje é bem comum uma família monoparental, ou seja, aquele em que a criança é criada apenas pela mãe ou pai. De acordo com relatos, meninas parecem mais adequadas a este estilo familiar, no entanto, embora melhor se adaptem a esta realidade, os adolescentes que são criados por ambos os pais são mais protegidos contra o abuso de drogas do que aqueles criados por famílias monoparental (5).

Todos os estudos parecem convergir para um consenso onde famílias disfuncionais, ou seja, aqueles em que há uma patologia no que diz respeito à comunicação, definição de regras e limites e falta de afeto, muitas vezes é o tipo mais comum de adolescentes dependentes de drogas. Corroborando esses achados, em um estudo com adolescentes de ambos os sexos que procuram identificar aspectos familiares relacionados com o consumo de álcool e drogas entre eles, foi constatado que a insatisfação com a família, a falta de comunicação familiar em que não há espaço para expressar sentimentos, ideias e opiniões, falta de respeito entre os membros e a falta de expressão de afeto e apoio. Por não se sentir bem-vindo na família podem levar o adolescente a se envolver em grupos 
desviantes que usam essas substâncias, muitas vezes, numa tentativa de compensar a lacuna deixada pela família ${ }^{(6)}$.

Estudos demonstraram que adolescentes de ambos os sexos com algum tipo de dependências, vem de famílias distantes que não executam atividades conjuntas, onde a coesão familiar, ou seja, a proximidade dos membros da família parece influenciar a dependência de drogas ${ }^{(7)}$.

Em estudo com adolescentes de ambos os sexos, encontraram uma correlação entre as famílias com falta de diálogo e envolvimento dos jovens com as drogas, outra questão que foi abordada em alguns estudos é a comunicação familiar inadequada, seria outra característica das famílias de jovens e principalmente de meninas dependentes de drogas ${ }^{(8)}$.

Já outros estudos revelou que entre dependente e não dependentes de drogas, um ambiente familiar onde não há espaço para se expressarem seus sentimentos, ideias e opiniões ou outra oportunidade de ser ouvido e/ou compreendido é indicado por adolescentes dependentes um dos aspectos negativos da dinâmica familiar, pois onde deveriam ter o conforto e a proteção, são deixados de lado e devem se virar com o turbilhão de sentimentos que afloram neles, em uma fase que já é difícil com a compreensão dos pais, imagina sem ${ }^{(9)}$.

Para esses autores, a falta de comunicação familiar é o principal motivo para que esses jovens encontrem nas drogas o apoio que não recebem, além de pertencerem a casas conflitantes e disfuncionais, parece que as meninas são mais vulneráveis para reagir a este ambiente conflituoso que os meninos, pois relatam níveis mais altos de estresse emocional resultante de brigas/discussões entre os pais ou a família em geral, indicando que o ambiente familiar influencia diretamente o estado emocional dessas meninas.

Existe um número de definições na literatura do estilo parental, onde de acordo com a definição que considera o estilo parental como um conjunto de atitudes, metas e modelos a serem seguidas, onde as estratégias usadas pelos pais para promover a socialização de seus filhos, e as práticas educativas são chamadas de estilo parental que é o resultado da integração de práticas educacionais ${ }^{(10)}$.

Vários estudos encontrados correlacionam-se a forma de educação dada aos filhos com a toxicodependência de adolescente, onde a falta de controle parental 
está mais associada à dependência de drogas em meninas. O apoio emocional fornecido pelos pais também parece ser uma prática educativa que afeta mais as meninas, ou seja, aqueles que nunca receberam apoio emocional dos pais são considerados de alto risco para toxicodependência no estudo (11).

Por outro lado, esses autores afirmam que as meninas precisam de maior apoio familiar como fator protetor contra a dependência de drogas, enquanto os meninos precisam de mais apoio de seus pares, sugerindo que as meninas aparentemente respondem mais ao ambiente familiar.

Outro aspecto interessante ao abordar a questão da população feminina adolescente é o papel da mãe, onde estudos deixa claro que é importante um bom relacionamento com a mãe, que desempenha um papel importante no desenvolvimento de comportamentos antissociais, incluindo o uso de drogas em meninas, mas não em meninos ${ }^{(12)}$.

O interesse dos pais na vida diária dos filhos, como saber quem são seus amigos, que lugares frequentam se estão bem na escola, também é uma importante prática educacional que influencia o vício em drogas na adolescência. As mães tendem a supervisionar os meninos de forma diferente, monitorando mais as filhas, 0 que as protege mais das drogas, porem uma supervisão inadequada (supervisão e ordens excessivas e/ou falta de padrões e limites) está diretamente relacionada ao uso de drogas na adolescência (13).

Porem quando os pais percebem o uso de drogas nos adolescentes, muita das vezes acha normal, tendo isso também uma influência muito negativa sobre a dependência, pois estes pais não podem ser eficazes no que diz respeito a disciplinar seus filhos, porque os mesmos consideram que o uso de drogas um fenômeno normal e esperado entre os adolescentes.

A falta de disciplina e os limites são frequentemente encontrados em adolescentes dependentes de drogas. Essas famílias parecem ter uma incapacidade de criar e educar seus filhos, resultando em precários laços familiares, onde essa falta de relação de confiança e carinho entre pais e filhos, o adolescente não aceito a autoridade e o estabelecimento de normas dos pais, pois sempre tiveram que lidar com seus problemas sozinhos ${ }^{(14)}$. 
Finalmente, cabe destacar que o presente estudo tem como objetivo suceder uma revisão integrativa da literatura a luz da temática família e drogas.

\section{METODOLOGIA}

O estudo foi desenvolvido por meio de pesquisa bibliográfica, de base qualitativa, de natureza descritiva e exploratória do tipo revisão integrativa de literatura. As etapas percorridas para a elaboração da presente revisão deram-se:

Pela definição da questão norteadora e objetivos da pesquisa - como os problemas decorrente do uso de drogas afetam os vínculos familiares? O foco norteou-se em levantar estudos que se contempla os eixos temáticos: Drogas - uso, abuso e tratamento; Família - estilo e vinculo; e Consequência - problemas, danos e causas.

Os critérios de inclusão estabelecidos para a seleção das publicações pautaram-se em considerar: a temática - famílias e a relação com as drogas, publicadas nos últimos 16 anos (entre 2000 e 2016), nos idiomas português, inglês e espanhol, que estivessem indexados nas bases de dados: Scielo, Medline, Lilacs, PePSIC, PsycINFO, Psychoanalytic Electronic Publishing e Redalyc cujas modalidades de produção fossem: artigos originais em estudo de caso, relato de experiência, estudo teórico, relato de pesquisa. Foram considerados estudos que explanassem os objetivos, os métodos e os resultados claramente definidos no resumo ou na introdução do documento e que tenham sido realizados no contexto familiar com ou sem a presença de todos os membros familiares. Foram exclusos do estudo os artigos que não corresponderam aos critérios de inclusão, em formato de teses, dissertações e materiais educativos, estudos em que não houvesse a descrição metodológica completa (objetivos, métodos e resultados).

Para busca da literatura no levantamento do material, foi utilizado o cruzamento do descritor família com as palavras-chave: relação - drogas - danos vinculo - estilo. Destaca-se que foi utilizado and entre o descritor e as palavraschave como operador booleano.

O levantamento do material deu-se por meio da leitura na íntegra dos resumos que foram verificados no sentido de considerar se as produções atenderam 
os critérios previamente estabelecidos. Elaborou-se um instrumento para a coleta das informações, composto pelos seguintes itens: eixos temáticos, classificação do tipo e/ou natureza de pesquisa, e classificação de referência.

As análises e a categorização dos dados coletados procederam-se em sínteses de estudos por definição do campo de análise da pesquisa/ estudo a partir da seguinte subdivisão: Distribuição dos estudos, segundo: ano, título, autor (ES); Distribuição dos estudos, segundo: objetivos e a problemática; Síntese dos estudos com delineamento de pesquisa em relação ao método: objetivo, tipo de pesquisa e resultados; e Síntese dos estudos quanto às considerações (conclusão) do artigo.

\section{RESULTADOS E DISCUSSÃO}

Foram selecionados 50 artigos que abordaram a temática família e 0 tratamento decorrente dos danos do uso das drogas, destes artigos 48 artigos abordam o uso de drogas, 2 artigos abordam o tratamento das drogas. Sendo 31 artigos abordam o vínculo familiar e 1 sobre estilo familiar, 2 artigos falam sobre a consequência do uso das drogas (problemas/ danos).

Em relação ao uso da palavra família, 36 artigos empregam no título dando destaque, 25 artigos apresenta a palavra drogas, 2 artigos empregam o tratamento, 1 artigo apenas faz referência aos problemas. As palavras que mais se repetem nos títulos são drogas e família.

A família é uma instituição complexa que congrega trajetórias individuais e que se expressa em arranjos diversificados e em espaços únicos ligados diretamente às transformações da sociedade. Esse sistema plural se reveste de diversas definições e controvérsias, e há relevância no que se refere ao processo de crescimento e desenvolvimento de seus membros, sendo que nela acontece o primeiro processo de socialização ${ }^{(4)}$.

No que refere aos objetivos 42 artigos cita a palavra família, 8 artigos cita o vínculo, 2 artigos citam estilo, 46 artigos fazem menção a palavra droga. É possível identificar que os objetivos dos 50 artigos selecionados são em sua maioria similares, diferenciados pelo verbo e a proposta do trabalho. 
Os pais tentam proteger os filhos para que não entrem em contato com tais substâncias, porém se esquecem de que na maioria das vezes foi através da vivencia com a própria família que estes efetuavam seu primeiro contato com fumo, álcool e outras lícitas. Porém, alguns jovens adolescentes na tentativa de sanar sua curiosidade, podem recorre às ilícitas, tais como a maconha, cocaína e os inalantes, sendo as drogas mais consumidas nesta fase buscando maior prazer, tentando outras emoções ou como fuga de seus problemas, ou ainda tentando se auto afirmar no seu grupo ${ }^{(1)}$.

Os estudos revelam que as características básicas das famílias de dependentes adolescentes de drogas, tais como: má gestão familiar, abandono, indisciplina e vigilância parenteral inadequada (pais desinteressados nas atividades diárias de seus filhos), processos de irritabilidade dos pais e família envolvendo interações baseadas em ameaças e medo. A relação entre a violência doméstica e dependência de drogas na adolescência também é conhecida. A presença de violência no ambiente doméstico faz com que esses adolescentes venham a sair de casa e acabam envolvidos com pares desviantes e, consequentemente, com o álcool e outras drogas ${ }^{(10)}$.

Muitos estudos mostram não só a influência dos pais, mas também dos irmãos, no desenvolvimento de dependência química na adolescência. Um fator importante, especialmente para as meninas, é a relação com as irmãs mais velhas. O modelo destas irmãs é tão importante como dos pais, e nos casos em que os pais não cumprem o seu papel como cuidadores, irmãs mais velhas têm maior responsabilidade de transmitir modelos saudáveis para essas meninas ${ }^{(1)}$.

Em um estudo recente, informou que para as meninas com pais separados cuidadas unicamente por sua mãe, para ter um bom relacionamento com as irmãs mais velhas parecem diminuir o risco de envolvimento com drogas na adolescência. Essa influência pode ser tão benéfica como colocar as meninas em risco, pois podem ter irmãs mais velhas que abusam de drogas, o que desempenha um papel no início do uso de drogas. A toxicodependência é uma forma de resolver os problemas desta fase da vida, especialmente se o adolescente não tem uma estrutura familiar em que você se sente apoiado, bem-vindos e bem orientados (15). 
Porém não se alega que a família é a única influência para o desenvolvimento de abuso de substâncias toxicas em adolescentes. O objetivo deste estudo centrase apenas nesta questão muito importante que não pode ser negligenciada quando se aborda esta questão, quer no tratamento ou prevenção. As famílias de mulheres usuárias de drogas parecem ser mais disfuncionais não só em sua dinâmica como um todo, mas em suas peculiaridades quanto à interação entre pais e filhos e entre irmãos.

Levando em conta os aspectos mencionados acima, pode-se dizer que a família hoje não mais segue o modelo padrão, porque não existe um único modelo familiar a ser seguido. E sim muitas maneiras, nós construímos em nosso dia a dia, no ambiente social que vivemos de acordo com nossos costumes, crenças e valores. Em outras palavras, a família tem seu próprio significado, especialmente indefinível. Assim, a diversidade de arranjos familiares hoje na sociedade brasileira é apresentada como um novo retrato da sociedade ${ }^{(16,17)}$.

As perguntas norteadoras do estudo ressaltam que é impossível pensar em um ambiente familiar onde o ciclo de vida esteja dissociado do desenvolvimento, movimento, crescimento, planejamento e etapas de cada membro que compõe a família; como compreender a história da família atual; crianças criadas por ambos os pais são mais protegidos contra o abuso de drogas do que aqueles criados em famílias monoparental; estudo com adolescentes de ambos os sexos, encontraram alguma correlação entre as famílias com falta de diálogo e envolvimento dos jovens com as drogas; uma comunicação familiar inadequada seria uma característica das famílias de jovens e principalmente de meninas dependentes de drogas; entre dependente e não dependente de drogas em um ambiente familiar onde não há espaço para se expressarem seus sentimentos há mais chance de ingressarem nas drogas.

Assim, a maneira como a família irá transmitir os valores sociais a seus filhos é o que pode propiciar, ou não, o uso abusivo de substância psicoativas por eles. Ou melhor, as práticas educativas e os estilos de criação utilizados pelas famílias podem comunicar normas desviantes para seus filhos, estimulando-os, desta forma, a irem buscar as drogas como fonte de prazer. Sabe-se que, no universo familiar, são vislumbrados diversos fatores que desencadeiam o uso de substâncias 
psicoativas, dentre elas a desestruturação o desequilíbrio do núcleo familiar e os pais como modelos no que diz respeito ao uso de drogas e álcool $(3,17,18)$.

Os resultados dos artigos indicam que apesar das reincidências, quando o jovem está empenhado em se tratar e juntamente com a família e um tratamento adequado se consegui faze-lo abandonar as drogas e começar uma nova etapa em sua vida.

Esse período de intensas transformações biopsicossociais pode conduzir a um desenvolvimento saudável quando o núcleo familiar oferece uma boa base de sustentação para as experimentações do adolescente. Contudo, por vezes, a dinâmica familiar é conturbada e não contribui para acolher os conflitos dos filhos em desenvolvimento, o que pode levá-los a se engajar em comportamentos sintomáticos, que favorecem a aproximação ao universo das drogas $(13,19)$.

Quanto às considerações dos autores nos artigos as análises permitiram reconhecer que a família é um fator primordial no tratamento e na recuperação dos dependentes químicos.

A linguagem familiar imprime a sintaxe, a semântica e a pragmática do como se relacionar, interagir e se comportar no seio da cultura. Os estudos apontam para a complexa influência da família, da escola e do grupo de amigos no caso da manifestação do uso abusivo de drogas, principalmente na adolescência. Os tratamentos são construídos, em sua maioria, na busca de engajamento e retenção daquele que abusa da droga, seja através das figuras significativas da família que se preocupam com ele, seja trabalhando de forma terapêutica o contexto familiar sob a ótica sistêmica (11).

Assim, se oferece os seguintes tipos de famílias: Nuclear: também chamada de biparental, composta por pai, mãe e filhos. Nela se destacam as funções social, política, sexual, econômica, reprodutiva e educativa. Extensas ou ramificadas: neste tipo de arranjo familiar, estão incluídas diferentes gerações na mesma família; Associativas: é o tipo de família na qual, as pessoas com as quais existem estreitos laços afetivos, também estão inseridos como membros; Adotivas: atribui-se esta denominação ao conjunto de pessoas que, ao se encontrarem, desenvolvem afinidades, passam a conviver considerando-se uma mesma família, independente de qualquer consanguinidade, tendo-se por exemplo: estudantes que vivem em 
residências universitárias ou que dividem apartamento ou outros espaços residenciais.

Duais ou monoparentais: este tipo de arranjo familiar é assim denominado por ser aquele formado por apenas dois membros: mãe-filho, pai-filho, esposoesposa / companheiro-companheira; ampliadas; são as famílias formadas sem necessidade de haver espaço físico comum, nem de desempenhar todas as funções tradicionais em conjunto. As pessoas se consideram como parentes, "psicologicamente falando". Recompostas: são àquelas famílias (marido, esposa e filhos ou um dos cônjuges e filhos), que após uma primeira experiência não bemsucedida, fazem uma nova tentativa com o mesmo ou com outro cônjuge; e Homossexuais: este tipo de família resulta da união de pessoas do mesmo sexo $(10,18)$.

Segundo experiências culturais e familiares, conhecimento, crenças, valores, circunstâncias de vida e também dificuldades interferem com o estilo da família a ser adotado por uma pessoa. Eles também fazem parte desse contexto, onde os fatores biológicos, psicológicos, sociológicos e espirituais, também influenciam (17).

A vida diária doméstica é caracterizada pela atenção às necessidades físicas e psicológicas dos diferentes membros da família. É no seu contexto social que protege a saúde e o tratamento da doença. A família é, de fato, a unidade básica dos cuidados de saúde; é o primeiro nível de cuidados de saúde. Nesse sentido, o cuidado familiar é a base do cuidado comunitário ${ }^{(18,19)}$.

Parece claro também que um dos principais sinais de resultado positivo do tratamento é a interface com o usuário melhora com a família, já que a dependência tem como uma das principais consequências da erosão dos vínculos afetivos e da perda das relações familiares ${ }^{(10)}$.

Assim pode se dizer que os valores familiares como espaço de recuperação, com as chamadas políticas de saúde atuais para a redução da oferta de leitos hospitalares e a criação de serviços alternativos de atendimento Saúde mental, para que o acompanhamento e evolução dos tratamentos para os interstícios da dinâmica familiar foram mobilizados para a inclusão de pessoas com transtornos mentais ${ }^{(13)}$.

\section{CONSIDERAÇÕES FINAIS}


Consideramos que este estudo buscou identificar as principais ações preventivas em relação ao uso de drogas na adolescência, se pode identificar que os adolescentes devem receber orientações a respeito dessas substâncias nos locais de seu convívio, como a escola, grupos de jovens, grupos de orientação em postos de saúde, na família, ou seja, nos locais onde eles possam se encontrar.

Nesse sentido, podemos concluir que a família é peça fundamental no processo de tratamento do adolescente uma vez que o acompanhamento familiar faz com que a mesma se aproxime mais do adolescente e ambos passem a se entender mais e situações como o diálogo e a amizade surjam nesse processo e que a escola deve criar ações preventivas em relação ao uso das drogas, pois assim, estará colaborando com as famílias que muitas vezes desconhecem as formas de cuidado, prevenção e auxílio que devem ser prestados as crianças e adolescentes que se encontram expostos ao mundo das drogas.

Assim ficou claro que as ações preventivas podem ser realizadas através de discussões, reflexões, conscientização do adolescente com o propósito de promover a mudança de comportamento, sendo que essas ações podem ser efetivas na tentativa de buscar diminuir o número de adolescentes que iniciam o uso dessas substâncias.

Porem pode se concluir que é importante estar atento para as peculiaridades e necessidades do adolescente, oferecendo o suporte adequado para suas demandas e que o contexto no qual ele está inserido é fundamental para o seu desenvolvimento biopsicossocial.

\section{REFERÊNCIAS}

1. Pozza AM. A Influência Familiar no Envolvimento dos Jovens com as Drogas. Interdisciplinar: Rev Eletrônica da Univar. 2011;6:154-157.

2. Seleghim MR, Félix MLO. Influência do Ambiente Familiar no Consumo de Crack em Usuários. Acta Paul Enferm. 2013;26(3):263-268.

3. Barbieri MF, Emer SO. O Impacto das Drogas na Família. Instituto Paulo Montenegro de Ação Social: 2009. 
4. Silva EA. Família, Abuso e Dependência de Drogas Desafios Clínicos e das Pesquisas. In: Anais da V Jornada de Psicologia no Hospital Municipal do Campo Limpo. Editora Blucher. 2015;1(6).

5. Silva J, Brands B, Adlaf E, Giesbrecht N, Simich L, Wright MGM. Familiares e Pessoas Conhecidas de Usuários de Drogas llícitas: recorte de opiniões sobre leis e políticas públicas de uma comunidade da Zona Oeste do Rio de Janeiro, Brasil. Rev Latino-am Enfermagem. 2009;7(Esp.):803-809.

6. Malta DC et al. Família e Proteção ao uso de Tabaco, Álcool e Drogas em Adolescentes. Pesquisa Nacional de Saúde dos Escolares. Rev Bras Epidemiol 2011;14(1) Supl.:166-177

7. Silva JÁ, Santos RA. Viva Sem Drogas: "Uso de Drogas na Adolescência". Anais Eletrônicos da I CIEGESI / I ENCONTRO CIENTIFFICO DO PNAP/UEG. 2012;22-23.

8. Nogueira JG. A Importância da Família na Problemática da Drogadição com Adolescentes sob o Olhar da Análise do Comportamento. [Graduação] Trabalho de Conclusão de Curso Faculdades Integradas Fafibe. 2009;40-43.

9. Alvarez SQ, Gomes GC, Xavier DM. Causas da Dependência Química e suas Consequências para o Usuário e a Família. Rev enferm UFPE on line. 2014;8(3):641-648.

10. Paiva FS, Ronzani TM. Estilos Parentais e Consumo de Drogas entre Adolescentes: Revisão Sistemática. Psicologia em Estudo. 2009;14(1):177-183.

11. Laranjeiras R, Oliveira RA, Nobre MRC, Berdardo WM. Usuários de Substâncias Psicoativas: abordagem, diagnóstico e tratamento. 2 ed. São Paulo: Conselho Regional de Medicina do Estado de São Paulo/ Associação Médica Brasileira; 2003.p120.

12. Moreno RS, Ventura RN, Brêtas RS. Ambiente Familiar e Consumo de Álcool e Tabaco entre Adolescentes. Revista Paulista de Pediatria. 2009;27(4).

13. Benchaya MC, Bisch NK, Moreira TC, Ferigolo M, Barros HM. Non-Authoritative Parents and Impact on Drug use: the perception of adolescent children. J Pediatr (Rio J). 2011;87(3):238-244.

14. Matosa MTS, Pintob FJM, Bessa MSJ. Grupo de Orientação Familiar em Dependência Química: Uma Avaliação sob a Percepção dos Familiares Participantes. Revista Baiana de Saúde Pública. 2008; 32(1):58-71. 
15. Pratta EMM, Santos MA. Uso de Drogas na Família e Avaliação do Relacionamento com os Pais Segundo Adolescentes do Ensino Médio. Rev Psico PUCRS. 2009;40(1):32-41.

16. Barbosa E, Porto L, Coelho A. A Importância da Família na Prevenção do uso de Drogas entre Crianças e Adolescentes: Papel Materno. Bogotá (Colombia). 2010;12(2):9-23.

17. Silva EA et al. As Drogas no Âmbito Familiar, sob a Perspectiva do Cinema. Psicologia: Teoria e Prática. 2008;10(1):214-222.

18. Fernandes LMS, Antoniassi Junior A. Drogas e a Família, uma discussão da literatura. Rev. Psicol Saúde e Debate. 2016; 2(edesp):73-85.

19. Matos LP, Lemgruber KP. A adolescência sob a ótica Psicanalítica: sobre o luto adolescente e de seus pais. Rev. Psicol Saúde e Debate. 2017:2(2):124-145. 